\title{
Fermentation of Panax notoginseng root extract polysaccharides attenuates oxidative stress and promotes type I procollagen synthesis in human dermal fibroblast cells
}

Shiquan You ${ }^{1,2,3+}$, Xiuqin Shi ${ }^{1,2,3+}$, Dan Yu ${ }^{1,2,3}$, Dan Zhao ${ }^{1,2,3}$, Quan An ${ }^{4}$, Dongdong Wang ${ }^{1,2,3}$, Jiachan Zhang ${ }^{1,2,3}$, Meng $\mathrm{Li}^{1,2,3^{*}}$ (D) and Changtao Wang ${ }^{1,2,3^{*}}$

\begin{abstract}
Background: Panax notoginseng is one of the most valuable traditional Chinese medicines. Polysaccharides in $P$. notoginseng has been shown to significantly reduce the incidence of human diseases. However the application of fermentation technology in Panax notoginseng is not common, and the mechanism of action of P. notoginseng polysaccharides produced by fermentation is still unclear. The specific biological mechanisms of fermented $P$. notoginseng polysaccharides (FPNP) suppresses $\mathrm{H}_{2} \mathrm{O}_{2}$-induced apoptosis in human dermal fibroblast (HDF) and the underlying mechanism are not well understood.

Methods: In this study, the effects of water extracted and fermentation on concentration of polysaccharides in $P$. notoginseng extracts were analyzed. After the $\mathrm{H}_{2} \mathrm{O}_{2}$-induced HDF model of oxidative damage was established, and then discussed by the expression of cell markers, including ROS, MDA, SOD, CAT, GSH-Px and MMP-1, COL-I, ELN, which were detected by related ELISA kits. The expression of TGF- $\beta / S$ mad pathway markers were tested by qRTPCR to determine whether FPNP exerted antioxidant activity through TGF- $\beta$ signaling in HDF cells.

Results: The polysaccharide content of Panax notoginseng increased after Saccharomyces cerevisiae CGMCC 17452 fermentation. In the FPNP treatment group, ROS and MDA contents were decreased, reversed the down-regulation of the antioxidant activity and expression of antioxidant enzyme (CAT, GSH-Px and SOD) induced by $\mathrm{H}_{2} \mathrm{O}_{2}$. Furthermore, the up-regulation in expression of TGF- $\beta, \operatorname{Smad} 2 / 3$ and the down-regulation in the expression of Smad7 in FPNP treated groups revealed that FPNP can inhibit $\mathrm{H}_{2} \mathrm{O}_{2}$-induced collagen and elastin injury by activating TGF- $\beta /$ Smad signaling pathway.

(Continued on next page)
\end{abstract}

\footnotetext{
* Correspondence: limeng@btbu.edu.cn; wangct@th.btbu.edu.cn

'Shiquan You and Xiuqin Shi contributed equally to this work.

'Beijing Advanced Innovation Center for Food Nutrition and Human Health,

Beijing Technology and Business University, Fucheng Road, Beijing 100048,

China

Full list of author information is available at the end of the article
}

(c) The Author(s). 2021 Open Access This article is licensed under a Creative Commons Attribution 4.0 International License, which permits use, sharing, adaptation, distribution and reproduction in any medium or format, as long as you give appropriate credit to the original author(s) and the source, provide a link to the Creative Commons licence, and indicate if changes were made. The images or other third party material in this article are included in the article's Creative Commons licence, unless indicated otherwise in a credit line to the material. If material is not included in the article's Creative Commons licence and your intended use is not permitted by statutory regulation or exceeds the permitted use, you will need to obtain permission directly from the copyright holder. To view a copy of this licence, visit http://creativecommons.org/licenses/by/4.0/ The Creative Commons Public Domain Dedication waiver (http://creativecommons.org/publicdomain/zero/1.0/) applies to the data made available in this article, unless otherwise stated in a credit line to the data. 
(Continued from previous page)

Conclusion: It was shown that FPNP could inhibit the damage of collagen and elastin induced by $\mathrm{H}_{2} \mathrm{O}_{2}$ by activating the TGF- $\beta /$ Smad signaling pathway, thereby protecting against the oxidative damage induced by hydrogen peroxide. FPNP may be an effective attenuating healing agent that protects the skin from oxidative stress and wrinkles.

Keywords: Panax notoginseng, Polysaccharides, Fermentation, Oxidative stress, TGF- $\beta /$ Smad signaling pathway

\section{Background}

Panax notoginseng (Burk) F.H. Chen is a kind of Chinese herb with high medicinal value. The root of Panax notoginseng contains many chemical components such as saponins, flavonoids, volatile oils, amino acids, polysaccharides, various trace elements, etc. [1-3]. Relevant studies have shown that $P$. notoginseng has many pharmacological effects, and it has been used in a large proportion of clinical treatment of cardiovascular diseases [4], cerebrovascular [5], blood, nervous and immune systems [6], as well as wound healing [7-10]. It is also added as the main ingredient in topical Chinese patent medicines, such as Yunnan Baiyao and Pianzaihuang, for hemostasis, antiulcer and protection against premature aging. In these prescriptions, $P$. notoginseng was not added directly but hydrolyzed or fermented by microorganisms [11]. By adding concentrated P. notoginseng fermented extracts, these prescriptions can promote the synthesis of collagen to reduce fine lines and wrinkles and effectively repair damage caused by sunlight or the external environment [12].

The aqueous extracts of $P$. notoginseng are rich in polysaccharides $[13,14]$. P. notoginseng polysaccharide (PNP) is a kind of heteroglycan which has been shown to have immunological [15], anticancer [16, 17], antihyperglycemic and anti-coagulation activity [18]. The PNP of high molecular weight is not conducive to absorption through the stratum corneum. To make PNP more efficient in protecting against the premature aging of the skin, low molecular weight PNP needs to be prepared. It has been reported that the conversion of macromolecular compounds into smaller forms using various microorganisms can improve their bioactivity $[19,20]$. Fermentation is the process of using microbial enzymes or microorganisms to convert raw materials into desired products [11, 20, 21]. In our previous study, $P$. notoginseng strains fermented by various microorganisms were selected. $P$. notoginseng polysaccharides fermented by Saccharomyces cerevisiae CMCC17452 which isolated in yellow rice wine wheat starter showed the highest antioxidant activity [22]. The fermentation and extraction conditions of FPNP were isolated and optimization. This FPNP showed the activity of antiinflammatory effects in the immortalized epidermal cell line $\mathrm{HaCaT}$ and anti-aging effects in HDF cells [23]. However, the relevance of these findings has yet to be fully documented, and the protective effect of FPNP on $\mathrm{H}_{2} \mathrm{O}_{2}$-induced oxidative stress and reduction of cellular collagen synthesis has not been studied.

Oxidative stress is a negative effect caused by the imbalance of oxidation and anti-oxidation in human body. Oxidative stress not only leads to increased protease secretion and production of a large number of oxidative intermediates, but also leads to increased collagen and elastin content in the dermis, further aging the skin [24]. However, antioxidant activity can be attributed to a variety of reactions and mechanisms, such as radical scavenging, reducing power, preventing chain initiation, etc. $[25,26]$. Antioxidant effects should not only have the ability to clear reactive oxygen species (ROS) but also have the role of up-regulated related antioxidant enzymes, regulating redox cell signals and gene expression [27]. $\mathrm{H}_{2} \mathrm{O}_{2}$ is a kind of ROS produced in healthy cells during cellular respiration and metabolism. High concentrations of $\mathrm{H}_{2} \mathrm{O}_{2}$ may induce various human degenerative diseases and aging [28]. The cell viability and concentration of several markers of oxidative damage, including the generation of ROS and malondialdehyde (MDA), glutathione peroxidase (GSH-Px) the enzyme activity of catalase (CAT) and superoxide dismutase (SOD), are all affected by $\mathrm{H}_{2} \mathrm{O}_{2}$. Damage by $\mathrm{H}_{2} \mathrm{O}_{2}$ has been shown to affect the degradation of collagen and procollagen synthesis [29]. Therefore, in this study, HDF cells treated with hydrogen peroxide $\left(\mathrm{H}_{2} \mathrm{O}_{2}\right)$ were used as a model to evaluate their antioxidant capacity. Transforming growth factor- $\beta$ (TGF- $\beta$ ) is a pluripotent cytokine that that is reported to be involved in procollagen synthesis and has an irreplaceable role. $\mathrm{H}_{2} \mathrm{O}_{2}$ destroys the TGF- $\beta /$ Smad pathway, further leading to reduction of type I procollagen [30] .

This study focused on detect the expression of oxidative damage markers and TGF- $\beta /$ Smad gene in HDF cells, to determine whether FPNP regulates antioxidant enzymes through TGF- $\beta$ signaling pathway, and then to study the mechanism of FPNP in HDF cells in antioxidant stress.

\section{Methods}

Reagents and instruments

Reagents and instruments were showed as following, including Saccharomyces cerevisiae CMCC17452, (isolated 
from yellow rice wine wheat in our laboratory); The P.notoginseng root (Wenshan in Yunnan Province, China); 2,2-diphenyl-1-picrylhydrazyl (DPPH) and ascorbic acid (Sigma-Aldrich,St. Louis, MO, USA); Fibroblast Medium (FM) (ScienCell, San Diego, CA, USA); Dulbecco's Modified Eagle's Medium (DMEM) and Fetal bovine serum (FBS), trypsin-EDTA and penicillin-streptomycin (Gibco Carlsbad, CA, USA); Cell lysis buffer for BCA Protein Assay Kit, Catalase (CAT), superoxide dismutase (SOD), Malondialdehyde (MDA) and ROS kits (Shanghai Beyotime Biotechnology Shanghai, China). Huma COL-1 (Collagen 1) ELISA Kit, Human Matrix metalloproteinase-1 (MMP-1) ELISA Kit and Huma Elastin (ELN) ELISA Kit (CUSABIO,Wuhan, China); EasyScript ${ }^{\circ}$ One-Step gDNA Removal and cDNA Synthesis SuperMix and TransStart ${ }^{\circ}$ Top Green qPCR SuperMix (TransGen Biotech Beijing, China). All other chemicals used were of high purity biochemistry grade. Olympus Inverted fluorescent microscope (Shanghai Tulsen Vision Technology Co., LTD, Shanghai, China); Infinite M200 PRO fluorescence marker (Deken Trading Co., LTD).

\section{Fermentation of RGE}

S. cerevisiae CMCC17452 was cultivated with YPD broth (Becton, Dickinson and Company, Sparks, MD, USA) at $28^{\circ} \mathrm{C}$ for $48 \mathrm{~h}$. P. notoginseng root (PNR) and pure water were were mixed to a ratio of 1 to 10 before sterilization for $15 \mathrm{~min}$ at $121^{\circ} \mathrm{C}$. S. cerevisiae CMCC17452 was inoculated into PNR solution at a concentration of $5 \%(\mathrm{~V} / \mathrm{V})$ and fermented at $28^{\circ} \mathrm{C}$ for $24 \mathrm{~h}$. The PNR solution without $S$. cerevisiae CMCC17452 was used as a blank control. Samples were centrifuged and the supernatant collected for analysis and named fermented $P$. notoginseng root liquid (FPNR) and water-extracted $P$. notoginseng root liquid (WPNR).

\section{Measurement of polysaccharide, ginsenoside and flavonoid content}

Polysaccharide content was measured using the sulfuric acid method [31]. The entire saponin content was determined using the modified vanillin-acetic acid assay with a standard curve of ginsenoside [32]. The entire flavonoid content was measured using a colorimetric assay with rutin as the standard sample.

\section{Measurement of antioxidant activity in vitro}

$\mathrm{DPPH}$, hydroxy free and superoxide anion free radical scavenging activity were performed following the published methods [10, 33].

\section{Cell culture and MTT assay}

Human dermal fibroblast cells (HDF, from Shanghai Institutes for Biological Sciences) were grown in FM medium containing 2\% FBS, $1 \%$ fibroblast growth additive and $1 \%$ penicillin/streptomycin at $37{ }^{\circ} \mathrm{C}$ in $5 \%$ $\mathrm{CO}_{2}$ atmosphere. We change culture medium every two days and split using $0.25 \%$ trypsin and $0.02 \%$ EDTA solution at 80 to $90 \%$ confluency.

Cells were seeded at $1 \times 10^{5}$ cells $/ \mathrm{mL}$ in a 96-well plate for $12 \mathrm{~h}$ and incubated with various concentration of FPNP $\left(0.25-2.5 \mathrm{mg} \cdot \mathrm{mL}^{-1}\right)$ for $12 \mathrm{~h}$. Next, the cells were incubated with a $10 \mu \mathrm{L}$ MTT solution $\left(100 \mathrm{mmol} \cdot \mathrm{L}^{-1}\right)$ for $4 \mathrm{~h}$. Subsequently, $100 \mu \mathrm{L}$ of dimethyl sulfoxide (DMSO, Sigma) was added to dissolve the purple formazan crystals. The optical densities of the solutions were quantified at a wavelength of $595 \mathrm{~nm}$ using a infinite M200 PRO fluorescence marker.

Cell survival is the percentage of viable cells compared to the control sample in the presence of the extract. Both untreated cells and DMEM cells of the same volume were used as controls, and each sample passed three independent analytical tests [34].

\section{Establishment of oxidative stress model}

The cells were inoculated on a 96-well plates at a concentration of $8 \times 10^{4}$ for oxidative stress analysis. When establishing the oxidative damage model of HDF caused by $\mathrm{H}_{2} \mathrm{O}_{2}$, according to cell viability, the $\mathrm{IC}_{50}$ concentration and time of the cells treated by $\mathrm{H}_{2} \mathrm{O}_{2}$ were determined using SPSS software. The concentrations of $\mathrm{H}_{2} \mathrm{O}_{2}$ were set at $1,10,25,50,100,250,500$ and $1000 \mu \mathrm{mol} \cdot \mathrm{L}^{-1}$.

\section{Determination of intracellular ROS, MDA, SOD, CAT and GSH-Px}

Superoxide dismutase (SOD) was assayed by the method as references [35]. The assay is based on total Superoxide Dismutase Assay Kit with WST-8 in line, relies on WST-8 [2-(2-methoxy-4-nitrophenyl)-3-(4-nitro- phenyl)-5-(2,4disulfophenyl)-2H-tetrazolium], which produces a highly water-soluble formazan dye, the reaction inhibited by SOD. Reactive Oxygen Species (ROS) level was detected by the method as references [35]. The assay is based on $2^{\prime}, 7^{\prime}$-dichlorofluorescin-diacetate (DCFH-DA), which can be oxidized into fluorescent DCF; The activity of catalase (CAT) was determined by the method as references [36], the catalase Assay Kit (Beyotime China) based on the protocols provided by the manufacturer. Glutathione peroxidase (GSH-Px) was estimated by the method as reference [37]. This is commercially available kit(Beyotime, China) according to the manufacturer's instructions.Malondialdehyde(MDA ) was estimated by the method as reference [38], this is lipid peroxidation MDA assay kit (Beyotime, China) based on the thiobarbituric acid.

Measurement of MMP-1, COL-I and ELN production Cells were seeded at $1 \times 10^{7}$ (cells/well) in a 6 well plate for $8-12 \mathrm{~h}$, then incubate with or without FPNP for 24 
h, furthermore treated with $\mathrm{H}_{2} \mathrm{O}_{2}$ to oxidative stress, HDF cells in 6-well plates were cultured again with FM from ScienCell (San Diego, CA, USA). After 24h, the supernatant was collected and the COL-I, MMP-1 and ELN content were measured using a corresponding assay ELISA kit purchased from Cusabio (Wuhan, China) (in strict accordance with the kit manufacturer's protocols) for anti-aging analysis.

\section{Quantitative reverse transcriptional PCR}

Cells were seeded at $1 \times 10^{7}$ (cells/well) in a 6 well plate for 8-12 h, then incubate with or without FPNPt for 24 $h$, furthermore treated with $\mathrm{H}_{2} \mathrm{O}_{2}$ to oxidative stress. Trizol was used to extract the total RNA from the cells according to the instructions, then the EasyScript ${ }^{\oplus}$ OneStep gDNA Removal and cDNA Synthesis SuperMix was used for cDNA synthesized according to the manufacturer's instructions. qPCRs were performed with TransStart $^{\oplus}$ Top Green qPCR SuperMix. Each reaction was performed in three replicate samples. The internal control gene is the GADPH gene. The relative expression levels were calculated using $2-\Delta \Delta \mathrm{Ct}$. The primer sequence list is based on the study of Jihong Wu et al [39].

\section{Statistical analysis}

Three separate experiments were conducted for all the experiments, each sample underwent three technical repeats and analyses. The mean standard deviation is going to be the results. One factor Analysis of Variance (ANOVA) and Dunnett test were used to analyze the data to determine which pairs were significantly different. Statistical analyses were conducted using GraphPad Prism7 (GraphPad Software, Inc., La Jolla, CA, USA). $p<$ 0.05 was considered significant.

\section{Results}

Fermentation of PNR by Saccharomyces cerevisiae CGMCC 17452

The concentrations of polysaccharides, ginsenosides and flavonoids were measured in water-extracted PNR (WPNR) and fermented PNR (FPNR) by S. cerevisiae CGMCC 17452. As can be seen from Table 1, there are significant differences between WPNR and FPNR in polysaccharides and ginsenosides, and during fermentation, the content of both is increased. The content of water-soluble flavonoids did not rise in FPNR. Compared to WPNR, FPNR had higher levels of polysaccharide, which may be because S. cerevisiae CGMCC 17452 strains plays an important role in the extraction of PNR.

\section{Extraction of WPNP and FPNP, and measurement of antioxidant activity}

The polysaccharides of WPNR and FPNR were extracted from the hot water extraction solution and fermentation
Table 1 Concentration of polysaccharides, ginsenosides and flavonoids in WPNR

\begin{tabular}{lll}
\hline $\begin{array}{l}\text { Concentration } \\
(\boldsymbol{\mu g} / \mathbf{m l})\end{array}$ & WPNR & FPNR \\
\hline Polysaccharides & $39.8 \pm 2.02^{\mathrm{a}}$ & $41.28 \pm 0.32^{\mathrm{b}}$ \\
Ginsenosides & $0.44 \pm 0.06^{\mathrm{c}}$ & $0.84 \pm 0.05^{\mathrm{d}}$ \\
Flavonoids & $6.14 \pm 1.44^{\mathrm{e}}$ & $5.98 \pm 0.79^{\mathrm{e}}$ \\
\hline
\end{tabular}

Values are presented as mean standard deviation a-e Means in the same column followed by different letters represent significant differences by concentration $(p<0.05)$

WPNR: water-extracted $P$. notoginseng root

FPNR: $P$. notoginseng root fermented with Saccharomyces cerevisiae

respectively by alcohol precipitation, then DEAESepharose Fast Flow anion exchange chromatography was used to purify and named "WPNP" and "FPNP". Three components of the polysaccharides were isolated and purified. The structure and compositions of purified polysaccharide were analyzed by infrared spectral and gel permeation chromatography respectively in our previous study [23].

DPPH radical scavenging activity, superoxide anion radical scavenging activity and hydroxyl radical scavenging activity were used to determine antioxidant activity. According to the three used assays, FPNP exhibited statistically significant higher antioxidant activity in comparison to WPNP (Table 2).

\section{Effects of FPNP on $\mathrm{H} 2 \mathrm{O} 2$ treated in HDF cells}

The cytotoxic character of FPNP and $\mathrm{H}_{2} \mathrm{O}_{2}$-induced toxicity was examined by MTT assay. When the concentration of FPNP reached $1.0 \mathrm{mg} \cdot \mathrm{mL}^{-1}$, cell proliferation activity still exceeded $100 \%$, indicating that FPNP has no toxicity to cells. When the FPNP concentration was 0.5 $\mathrm{mg} \cdot \mathrm{mL}^{-1}$, the cell survival rate was $112.8 \%$, seeing Fig. 1a. The results show that the low concentration of FPNP solution had a proliferation effect and an effect on promote the proliferation of HDF cells.

For further confirmation, we also tested the effect of FPNP on $\mathrm{H}_{2} \mathrm{O}_{2}$-induced cytotoxicity. Figure $1 \mathrm{~b}$ shows the cell survival rate when different concentrations of $\mathrm{H}_{2} \mathrm{O}_{2}$ were used to stimulate HDF for $2 \mathrm{~h}$. With the increase in $\mathrm{H}_{2} \mathrm{O}_{2}$ concentration, the $\mathrm{HDF}$ survival rate gradually decreases. Finally, the oxidative damage model of HDF was established by treating HDF with $75 \mu \mathrm{mol} \cdot \mathrm{L}^{-1} \mathrm{H}_{2} \mathrm{O}_{2}$ as the optimum dose of this study.

As shown in Fig. 1c, $\mathrm{H}_{2} \mathrm{O}_{2}$-treated HDF cells showed a decreased survival rate, while treatment by FPNP cells showed a dose-dependent recovery of reduced cell activity. $0.25 \mathrm{mg} \cdot \mathrm{mL}^{-1}$ of FPNP recovered viability by $38.96 \%$ compared with $\mathrm{H}_{2} \mathrm{O}_{2}$-damaged cells. The viabilities of cells treated with $\mathrm{H}_{2} \mathrm{O}_{2}$ and FPNP $(0.25,0.5$ and 1.0 $\left.\mathrm{mg} \cdot \mathrm{L}^{-1}\right)$ showed statistical difference $(p<0.01)$, and the three levels of $0.25,0.5$ and $1.0 \mathrm{mg} \cdot \mathrm{mL}^{-1}$ of treatment 
Table 2 Antioxidant effects of WPNP and FPNP

\begin{tabular}{lllll}
\hline Sample & $\begin{array}{l}\text { Concentration } \\
(\mathbf{m g} / \mathbf{m l})\end{array}$ & $\begin{array}{l}\text { DPPH radical scavenging } \\
\text { activity (\%) }\end{array}$ & $\begin{array}{l}\text { Hydroxy free radical scavenging } \\
\text { activity (\%) }\end{array}$ & $\begin{array}{l}\text { Superoxide anion free radical scavenging } \\
\text { activity (\%) }\end{array}$ \\
\hline WPNP & 0.5 & $13.82 \pm 0.12^{\mathrm{ab}}$ & $33.45 \pm 0.47^{\mathrm{a}}$ & $56.48 \pm 1.16^{\mathrm{a}}$ \\
& 1 & $15.16 \pm 0.69^{\mathrm{ab}}$ & $68.78 \pm 0.93^{\mathrm{b}}$ & $63.71 \pm 0.70^{\mathrm{b}}$ \\
2 & $51.71 \pm 0.44^{\mathrm{c}}$ & $75.54 \pm 0.35^{\mathrm{cd}}$ & $66.42 \pm 2.49^{\mathrm{c}}$ \\
& 2.5 & $57.27 \pm 0.48$ & $79.03 \pm 0.62^{\mathrm{cd}}$ & $68.39 \pm 2.06^{\mathrm{d}}$ \\
$\mathrm{FPNP}$ & 0.5 & $76.14 \pm 1.20^{\mathrm{d}}$ & $96.55 \pm 0.06^{\mathrm{e}}$ & $76.35 \pm 0.65^{\mathrm{e}}$ \\
& 1 & $17.22 \pm 0.34^{\mathrm{a}}$ & $31.51 \pm 0.81^{\mathrm{a}}$ & $68.28 \pm 1.54^{\mathrm{ab}}$ \\
& 2 & $40.79 \pm 067^{\mathrm{b}}$ & $63.64 \pm 1.19^{\mathrm{b}}$ & $69.54 \pm 0.62^{\mathrm{ab}}$ \\
2.5 & $49.24 \pm 0.61^{\mathrm{c}}$ & $76.92 \pm 0.36^{\mathrm{c}}$ & $72.21 \pm 0.42^{\mathrm{cd}}$ \\
5 & $57.13 \pm 0.16^{\mathrm{d}}$ & $90.19 \pm 0.10^{\mathrm{d}}$ & $72.49 \pm 1.53^{\mathrm{cd}}$ \\
\hline
\end{tabular}

Values are presented as mean standard deviation a-e Means in the same column followed by different letters represent significant differences by concentration $(p<0.05)$

concentration were selected for further study. These results suggest that FPNP can protect HDF cells from $\mathrm{H}_{2} \mathrm{O}_{2}$-induced cell viability reduction.

\section{Effects of FPNP on H2O2-induced ROS generation, MDA production and ABTS scavenging activities in HDF cells} The statistics of the experimental data are shown in Fig. 2a, with the stimulation of $\mathrm{H}_{2} \mathrm{O}_{2}$, ROS levels were significantly augmented. The positive control was ascorbic acid when evaluating the antioxidant effect of FPNP. After treatment with $0.1 \mathrm{mg} \cdot \mathrm{mL}^{-1}$ of ascorbic acid, the ROS level significantly decreased than $\mathrm{H}_{2} \mathrm{O}_{2}$-treated group $(p<0.01)$. FPNP also markedly reduced the levels of intracellular ROS $(p<0.01)$, compared with the $\mathrm{H}_{2} \mathrm{O}_{2}$ treated model group. When $\mathrm{H}_{2} \mathrm{O}_{2}$-induced cells were treated with $0.5 \mathrm{mg} \cdot \mathrm{mL}^{-1}$ of FPNP, the ROS level was reduced by $57.29 \%$. These results show that FPNP can protect cells from $\mathrm{H}_{2} \mathrm{O}_{2}$ oxidative damage by reducing the ROS level.

With the stimulation of $\mathrm{H}_{2} \mathrm{O}_{2}$, the effects of FPNP on MDA in cells are shown in Fig. $2 \mathrm{~b}$ and total antioxidant capacity is shown in Fig. 2c. The positive control was ascorbic acid and was statistically analyzed $(p<0.01)$. In
$\mathrm{H}_{2} \mathrm{O}_{2}$-induced $\mathrm{HDF}$ cells, $0.25,0.5$ and $1.0 \mathrm{mg} \cdot \mathrm{mL}^{-1}$ FPNP decreased the MDA content $(p<0.01)$ and increased the total antioxidant capacity of the cells $(p<$ 0.05). These results show that FPNP can protect cells from $\mathrm{H}_{2} \mathrm{O}_{2}$-induced damage by reducing their MDA content and increasing their total antioxidant capacity.

\section{Effects of FPNP on CAT, GSH-Px and SOD activity in H2O2-induced HDF cells}

The activity of antioxidant enzymes in cells were measured, including CAT, GSH-Px and SOD. See Figs. 3, $0.25,0.50$, and $1.00 \mathrm{mg} \cdot \mathrm{mL}^{-1} \mathrm{FPNP}$ increased CAT, GSH-Px and SOD activity compared with the $\mathrm{H}_{2} \mathrm{O}_{2}$ treated model group. As can be seen from Fig. 3a, CAT activity was significantly increased in FPNP group, compared with model group $(p<0.01)$, with a significant difference, and was consistent with that of the control group ( $p>0.05)$. SOD activity was highest, when the concentration of FPNP was $0.50 \mathrm{mg} / \mathrm{ml}$. the difference between the $\mathrm{H}_{2} \mathrm{O}_{2}$ treatment model group and the control group was statistically significant $(p<0.01)$. Under these conditions, the effects are similar to those of 0.10 $\mathrm{mg} \cdot \mathrm{mL}^{-1}$ of ascorbic acid, as shown in Fig. 3b. When
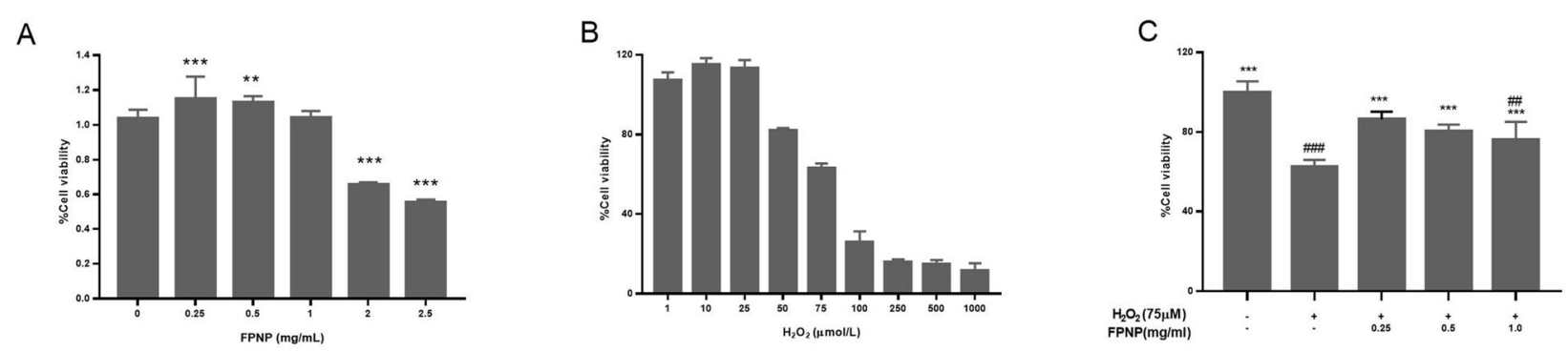

Fig. 1 Effects of FPNP on $\mathrm{H}_{2} \mathrm{O}_{2}$-induced cytotoxicity in HDF cells. (a) Effects of FPNP on the viability of HDF cells. (b) Effects of HDF survival rate caused by $\mathrm{H}_{2} \mathrm{O}_{2}$. (c) FPNP prevents $\mathrm{H}_{2} \mathrm{O}_{2}$-induced cytotoxicity in $\mathrm{HDF}$ cells. The data is presented as the mean \pm SD of the six experiments in each group. Number signs indicate a highly significant difference from the control cells. \#\#: $p<0.01$; \#\#\#: $p<0.001$. Asterisks indicate a highly significant difference from the $\mathrm{H}_{2} \mathrm{O}_{2}$-treated cells. ${ }^{*}: p<0.05,{ }^{* *}: p<0.01$ 

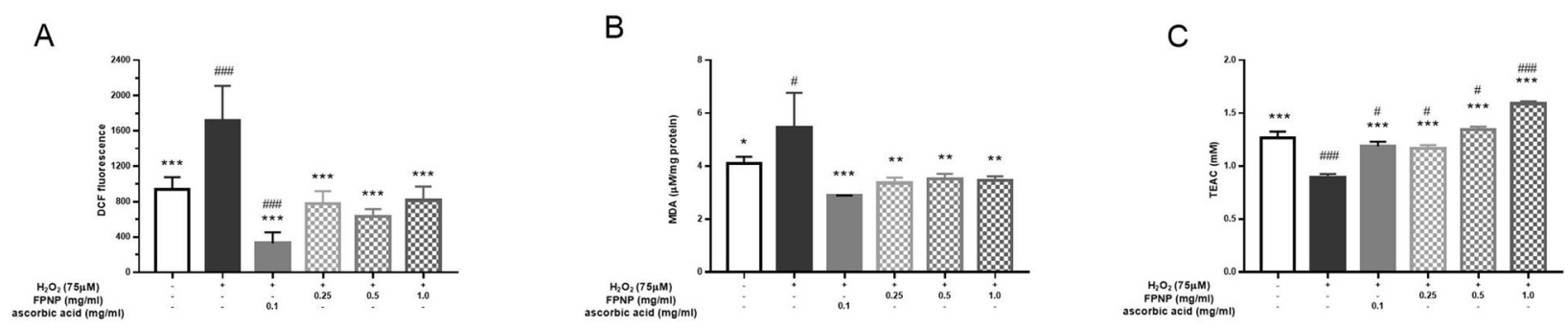

Fig. 2 (a) Intracellular ROS scavenging capacities of different concentrations of FPNP of $\mathrm{H}_{2} \mathrm{O}_{2}$-induced oxidative stress in HDF cells. (b) Effects of FPNP on MDA content in $\mathrm{H}_{2} \mathrm{O}_{2}$-induced oxidative stress in $\mathrm{HDF}$ cells. (c) Effects of FPNP on total antioxidant capacity in $\mathrm{H}_{2} \mathrm{O}_{2}$-induced oxidative stress in HDF cells. All data is shown as the mean \pm SD of at least three independent experiments. Number signs indicate a highly significant difference from the control cells. \#\#: $p<0.01$; \#\#\#: $p<0.001$. Asterisks indicate a highly significant difference from the $\mathrm{H}_{2} \mathrm{O}_{2}$-treated cells. ${ }^{*}: p<0.05$, **: $p<0.01$

the concentrations of FPNP were $0.50 \mathrm{mg} \cdot \mathrm{mL}^{-1}$ and 1 $\mathrm{mg} \cdot \mathrm{mL}^{-1}$, the level of GSH-Px activity was increased significantly compared with model group $(\mathrm{p}<0.01)$, as shown in Fig. 3c.

$0.25,0.50$, and $1.00 \mathrm{mg} \cdot \mathrm{mL}^{-1}$ of FPNP significantly increased the expression of CAT, GSH-Px and SOD relative to mRNA expression. The expression of the CAT-expression mRNA level was similar in the FPNP treatment group at different concentrations and markedly increased in the $\mathrm{H}_{2} \mathrm{O}_{2}$-treated group $(p<0.01)$, compared with the model group. as shown in Fig. 3d. There was an apparent dose-dependent relationship between the expression level of SOD-related mRNA and FPNP dosage: as the concentration of FPNP increased, the expression level increased. As can be seen from Fig. 3e, it was similar to the control group, with no significant difference, when the concentration of FPNP was 1.00 $\mathrm{mg} \cdot \mathrm{mL}^{-1}$.The expression of GSH-Px mRNA in the 1.00 $\mathrm{mg} \cdot \mathrm{mL}^{-1}$ FPNP treatment group was the highest, and there was little difference from that of the control group, as shown in Fig. 3f. In summary, these results clearly show that FPNP can repair oxidative stress damage by increasing the activity of CAT, GSH-Px and SOD, and the expression of related mRNA in HDF cells.

\section{Effects of FPNP on H2O2-induced MMP-1, col-I and ELN contents}

$\mathrm{H}_{2} \mathrm{O}_{2}$ affects collagen and elastin synthesis by stimulating MMP-1. As shown in Fig. 4a, $1.00 \mathrm{mg} \cdot \mathrm{mL}^{-1}$ of FPNP significantly reduced the content of MMP- 1 in the culture medium of $\mathrm{H}_{2} \mathrm{O}_{2}$-induced HDF cells $(p<0.01)$ and

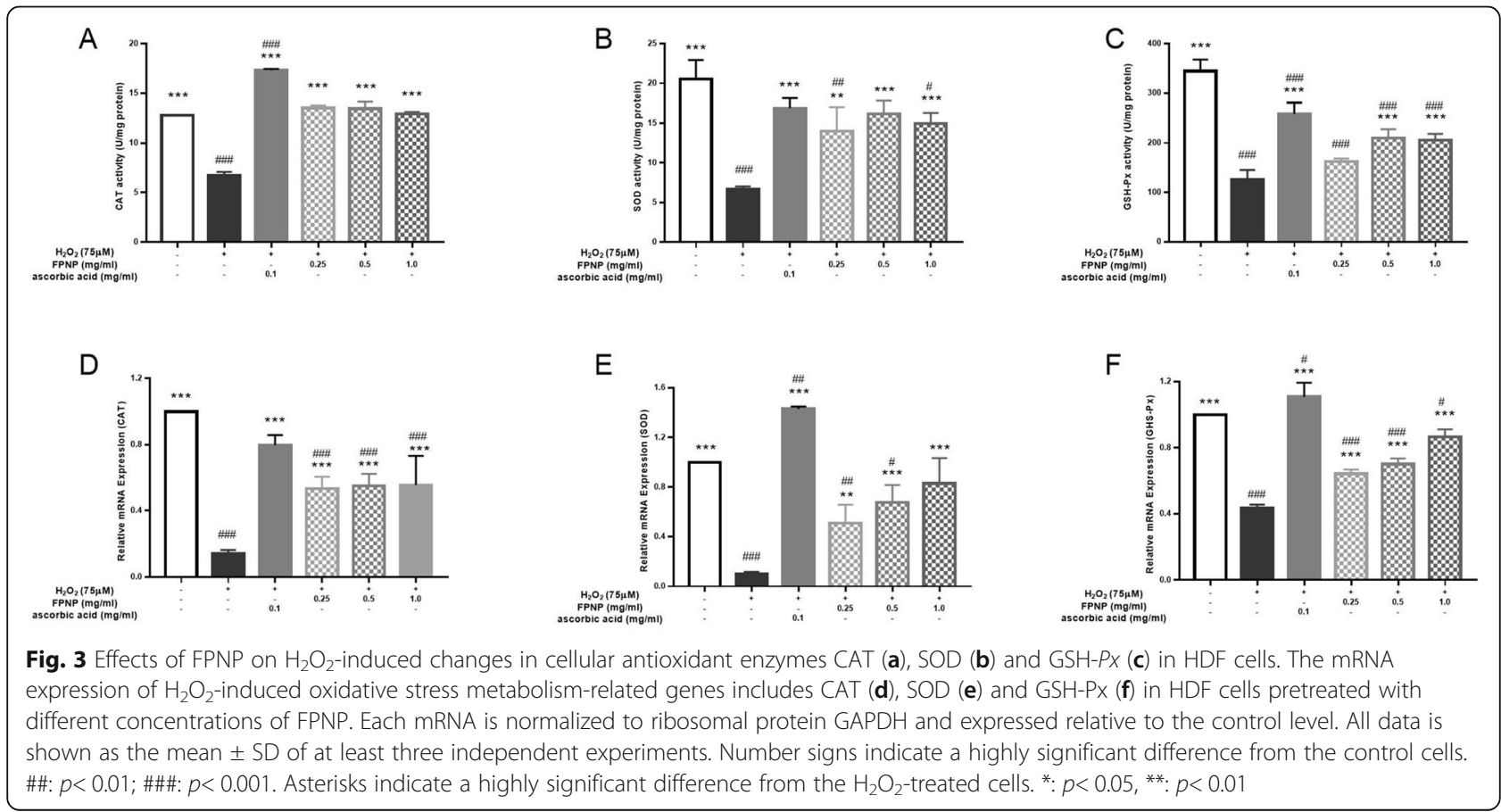




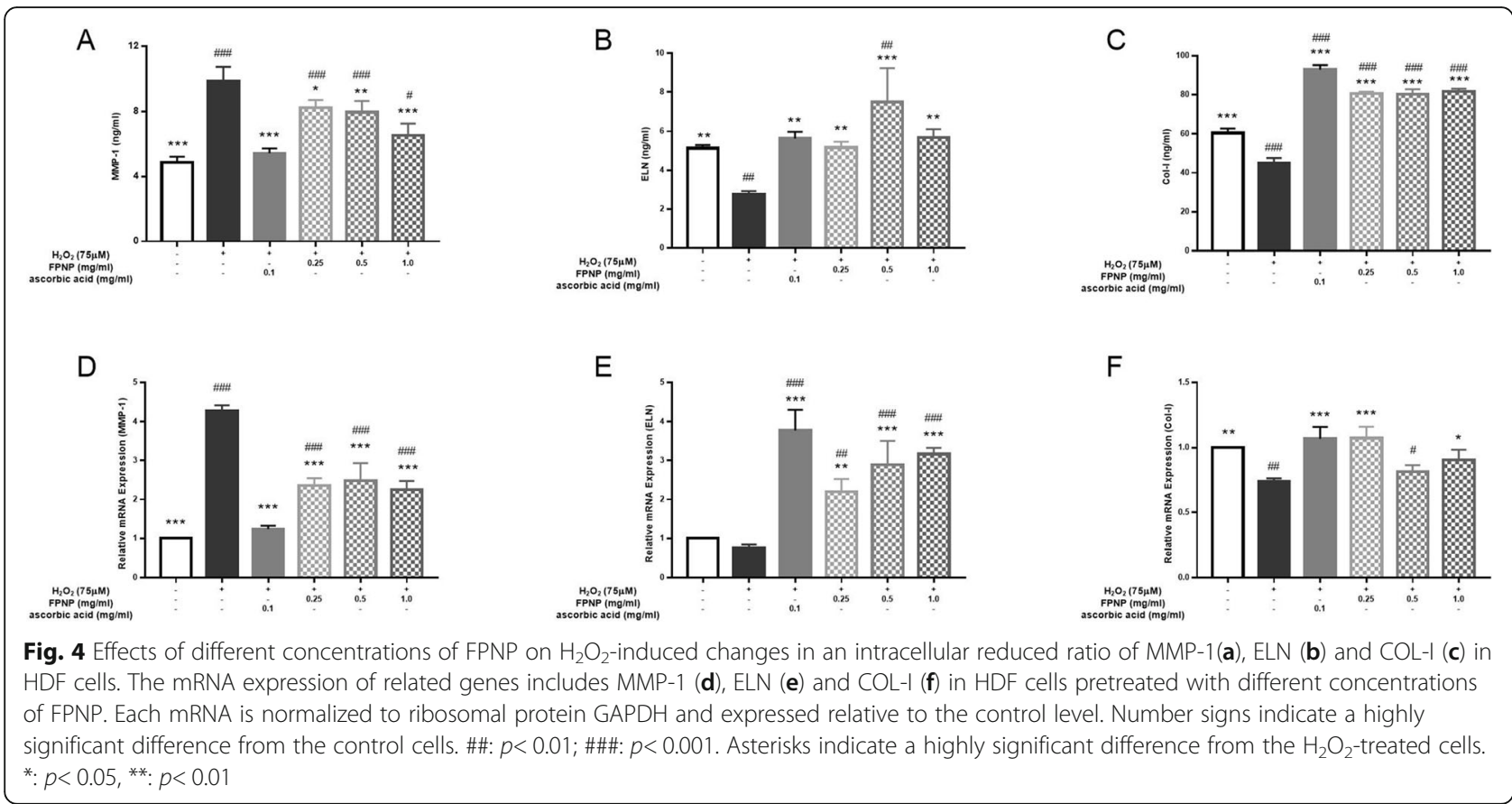

achieved anti-aging effects. Effect of different concentrations of FPNP on secretions of ELN and Col-I as shown in Fig. 4b and Fig. 4c, FPNP can significantly increase secretions of ELN and Col-I in $\mathrm{H}_{2} \mathrm{O}_{2}$-induced HDF cell cultures. There was no significant difference between $0.50 \mathrm{mg} \cdot \mathrm{mL}^{-1}$ FPNP and $0.10 \mathrm{mg} \cdot \mathrm{mL}^{-1}$ ascorbic acid, while $0.50 \mathrm{mg} \cdot \mathrm{mL}^{-1}$ of FPNP significantly improved the contents of ELN and Col-I.

The results of qRT-PCR show that Compared with the control group, MMP-1 mRNA expression in HDF cells was significantly increased $(p<0.01)$, and the expression of Col-I and ELN mRNA was inhibited. After FPNP treatment, the expression of MMP-1 mRNA decreased, indicating that $0.25,0.50$, and $1.00 \mathrm{mg} \cdot \mathrm{mL}^{-1}$ of $\mathrm{FPNP}$ can inhibit the upregulation of MMP-1 mRNA expression in the $\mathrm{H}_{2} \mathrm{O}_{2}$-treated model group $(p<0.01)$, seeing Fig. 4d. With FPNP treatment, both ELN and Col-I mRNA expression increased over the $\mathrm{H}_{2} \mathrm{O}_{2}$-treated model group and came close to those of the control level $(p<0.01$; Fig. $4 \mathrm{e}$ and $\mathrm{f})$. This indicates that FPNP can effectively improve the secretion of ELN and Col-I and achieve anti-aging effects.

\section{TGF- $\beta$ /Smad pathway signaling in HDF cells}

Transforming growth factor- $\beta$ (TGF- $\beta$ ) has been recognized as a strong mediator in the synthesis of collagen and elastin. To clarify the effects of FPNP on Col-I and ELN synthesis, the expression of TGF-Smad1, Smad2, Smad3 and Smad7 mRNA in HDF induced by $\mathrm{H}_{2} \mathrm{O}_{2}$ were detect by qRT-PCR. Seeing in Fig. 5 , the results of qRT-PCR showed that compared with those of the control group, $\mathrm{H}_{2} \mathrm{O}_{2}$ significantly downregulated the expressions of TGF- $\beta 1$ and Smad $2 / 3 \quad(p<0.01)$, while FPNP reversed this effect. $1.00 \mathrm{mg} \cdot \mathrm{mL}^{-1}$ of FPNP recovered the expression of $\operatorname{smad} 2, \operatorname{smad} 3$ and $\operatorname{smad} 4$ mRNA expression 3.58-fold, 7.53-fold and 1.84-fold respectively compared with the $\mathrm{H}_{2} \mathrm{O}_{2}$ group, and increased TGF- $\beta 1$ mRNA 3.04-fold compared with the $\mathrm{H}_{2} \mathrm{O}_{2}$ group, as shown in Fig. 5a-d. In addition, we investigated the effect of FPNP on the expression of smad7, which a negative factor in the TGF- $\beta /$ Smad pathway. Seeing Fig. 5 e, 1.00 $\mathrm{mg} \cdot \mathrm{mL}^{-1}$ of FPNP downregulated the Smad7 mRNA expression level by $62.84 \%$ compared with the $\mathrm{H}_{2} \mathrm{O}_{2}$ group. This experimental evidence suggests that FPNP leads to the overexpression of TGF- $\beta$ in HDF, which in turn inhibits $\mathrm{H}_{2} \mathrm{O}_{2}$-induced collagen and elastin injury.

\section{Discussion}

P. notoginseng polysaccharide (PNP) is a kind of heteroglycan which has been shown to have immunological [15], anticancer [16, 17], anti-hyperglycemic and anticoagulation activity [18]. It has been reported that the conversion of macromolecular compounds into smaller forms using various microorganisms can improve their bioactivity $[19,20]$. With reference to the lactic acid bacteria fermentation of Panax notoginseng, HPLC analyses showed that the fermentation increased the content of Panax notoginsenosides and other active substances reported in previous studies [40], in our study, the fermented $P$. notoginseng polysaccharide (FPNP) were prepared by $S$. cerevisiae. The results showed that fermentation increased the polysaccharide content of Panax 


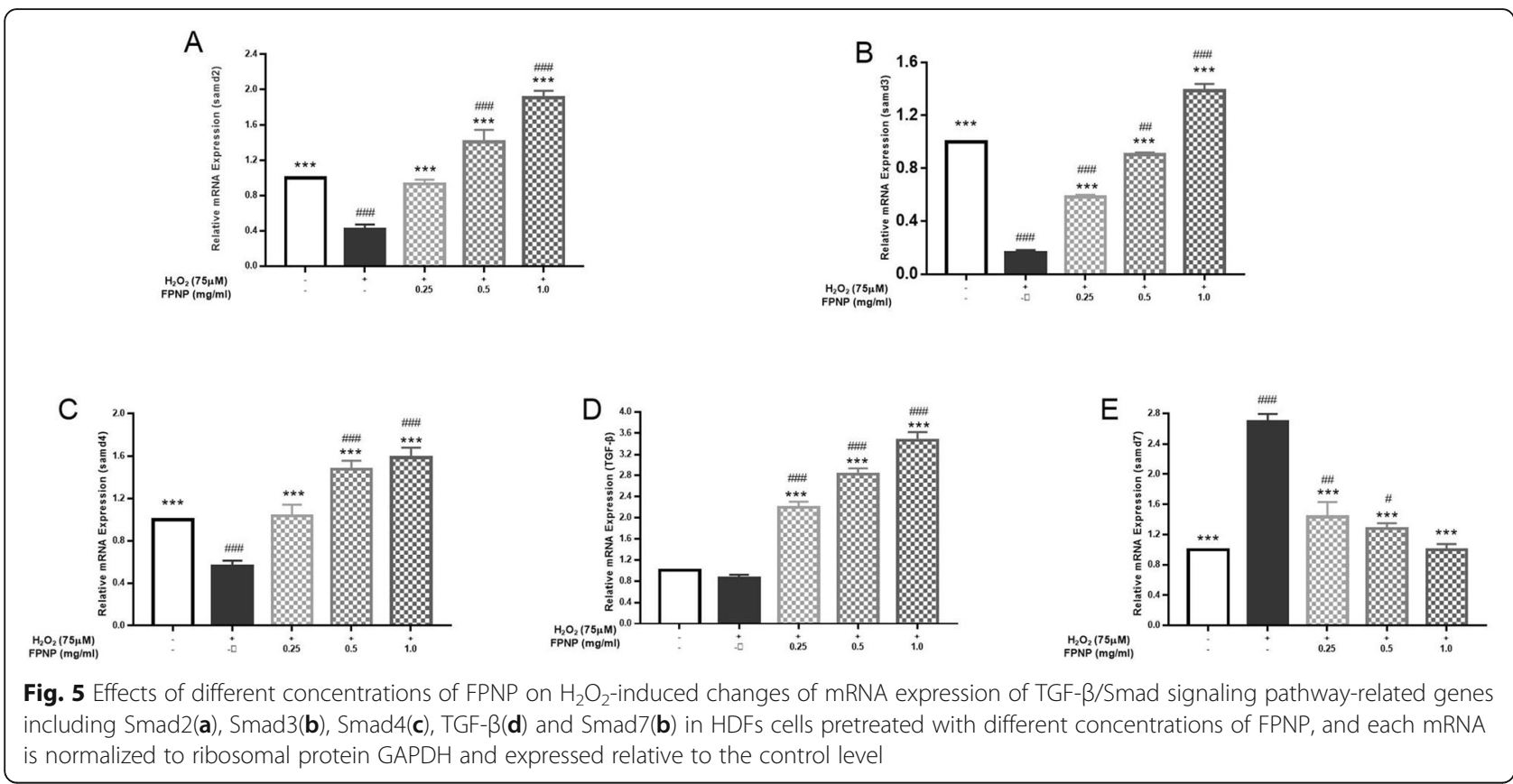

notoginseng, which was in accordance with literature reports. HDF cells treated with hydrogen peroxide were used as a model to simulate the oxidative stress response. We used HDF cells treated with hydrogen peroxide as a model to simulate the oxidative stress response, so as to study the mechanism of antioxidant stress injury caused by the fermentation of Panax notoginseng polysaccharides.

In skin aging, histological and ultrasonic structural studies have shown that enhanced epidermal thickness and changes in connective tissue are common features of damaged skin [41-44]. Collagen and elastin are the proteins responsible for the strength and elasticity of the skin. Ultraviolet radiation triggers the activation of MMPs, which attack and degrade collagen and elastin, leading to photoaging of the skin. Inhibition of MMPs is considered an effective strategy to prevent UV-induced photoaging. Oxidative stress could induce matrix metalloproteinase-1 (MMP-1) [45], In this study, hydrogen peroxide accelerated the production of collagensoluble MMP-1 in cells. MMP-1 degrades collagen, which are the main structural proteins of the dermal extracellular matrix (ECM), and maintain the strength and elasticity of the skin [46]. We found FPNP (1.00 $\mathrm{mg} \cdot \mathrm{mL}^{-1}$ ) treatment can reduce the production of MMP-1. FPNP can reduce the loss of collagen and elastin in cells. On this basis, FPNP not only inhibits the expression of MMP-1, but also promotes the expression of structurally related proteins in extracellular matrix to exert its protective effect. Our results support that FPNP can be used to prepare cosmetics to repair and regenerate essential proteins in photo-aging skin. Column chromatography was used to isolate Panax notoginseng root, and two new polysaccharides, MAP and MRP5A, have antioxidant and anti-aging effects, reported in previous studies [47]. In subsequent studies, the structure of FPNP can be separated to study the specific components that play a role.

Smad protein is the downstream transmembrane receptor of TGF- $\beta$ and is an important regulatory molecule of TGF- $\beta$ superfamily signaling [48]. Oxidative stress can induce MMPs and pro-inflammatory cytokines in cells. TGF- $\beta$ promotes the synthesis of collagen type I [41]. Therefore, preparing anti-inflammatory compounds for inflammation in advance seems to be a strategy to improve skin oxidative stress. Hydrogen peroxide promotes the secretion of Smad7, which subsides after FPNP treatment. At the same time, FPNP promotes the expression of TGF- $\beta 1$, Smad2, Smad3, Smad4. It is possible that FPNP elevates type I collagen levels in part by enhancing the TGF- $\beta$ /Smad pathway. Previous studies [45] have demonstrated that UVB induced lipid peroxidation, apoptosis and MMP-1 expression in fibroblasts are similar to our results, indicating that oxidative stress damage caused by hydrogen peroxide is similar to that caused by UVB.

It is reported that ROS is related to the production of MMP and the breakdown of collagen [43]. Therefore, controlling ROS levels seems to be a major mechanism through which plant compounds with antioxidant activity can be particularly effective. The ethanol extract from Dalbergia bug protects skin keratinocytes from oxidative stress by inhibiting the production of reactive oxygen species. Topical application of patchouli alcohol inhibit UV-induced aging of 


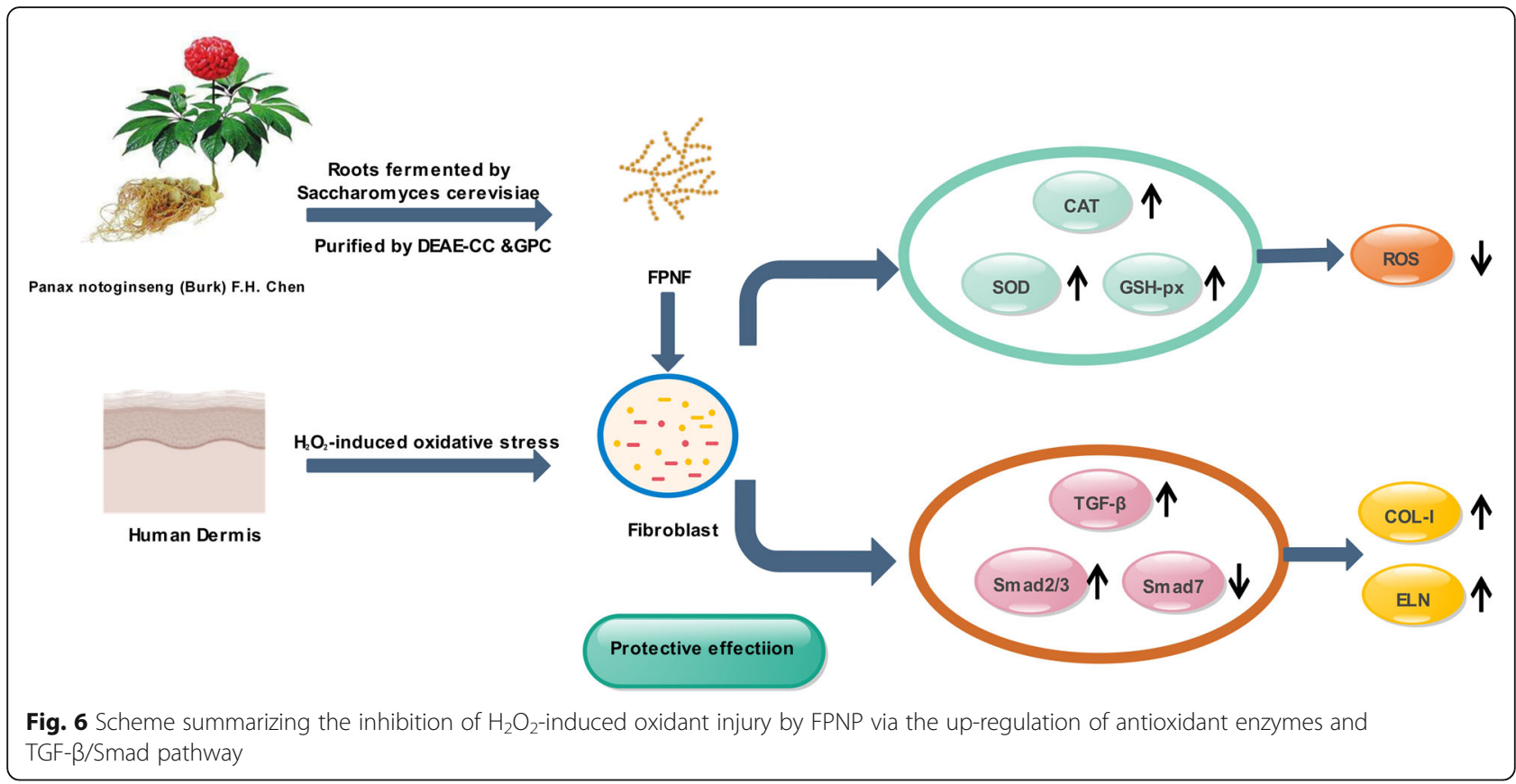

mouse skin caused by reactive oxygen species [49]. In our study, as shown in Fig. 6, FPNP cleared ROS, which explained that in HDF cells, increased SOD, CAT and GSH-Px levels. These protective properties of FPNP seem to be accomplished by up-regulating the expression of cellular antioxidant genes.

\section{Conclusion}

We have provided evidence that FPNP represses $\mathrm{H}_{2} \mathrm{O}_{2}-$ induced HDF fibroblast injury, including the elevation of ROS and MDA content, decreased expression of antioxidant-related enzymes (CAT, GSH-Px and SOD), increased MMP-1 content and reduced collagen and elastin. Moreover, FPNP efficiently $\mathrm{H}_{2} \mathrm{O}_{2}$-mediates oxidative reparation, such as the elevation of collagen and elastin content through the TGF- $\beta /$ Smad signaling pathway. Ultimately, we propose that FPNP may be an effective attenuated healing agent for protecting the skin against oxidative stress and wrinkles.

\section{Abbreviations}

FPNP: Fermented $P$. notoginseng polysaccharides; FPNR: Fermented $P$. notoginseng root liquid; WPNR: Water-extracted $P$. notoginseng root liquid; HDF: Inhuman dermal fibroblast; PNP: P. notoginseng polysaccharide; PNR: $P$. notoginseng root; ROS: Reactive oxygen species; MDA: Malondialdehyde; GSH-Px: Lutathione peroxidase; CAT: Catalase; SOD: Superoxide dismutase; TGF- $\beta$ : Transforming growth factor- $\beta$; DPPH: 2,2-diphenyl-1-picrylhydrazyl; FM: Fibroblast Medium; DMEM: Dulbecco's Modified Eagle's Medium; FBS: Fetal bovine serum; MMP-1: Matrix metalloproteinase-1; H2-DCFDA: 2', 7' -dichlorodihydrofluorescein diacetate

\section{Acknowledgements}

Upon the completion of this manuscript, we would like to express our heartfelt thanks to Beijing Technology and Business University for providing us with an excellent learning platform, a rich scientific research environment, a warm campus environment, and an excellent and responsible and kind teacher. We would also like to thank the editors and review experts who will carefully review our manuscript and suggest reasonable modifications; In addition, I also want to thank my parents and friends for the care in my study and life! Finally, I would like to express my heartfelt thanks to all the friends who have helped me.

\section{Authors' contributions}

$\mathrm{ML}$, CTW and QA provided the concept and designed the experiment; SQY and XQS performed the experiments; DY, DZ, DDW and JCZ analyzed the data; SOY and XOS wrote the manuscript. All authors have read and approved the final manuscript.

\section{Funding}

This work was supported by the Yunnan Science and technology project (2018ZF005). The founder helped pay for this study.

\section{Availability of data and materials}

The data used and/or investigated during the present study are available from the corresponding author upon reasonable request. t.

Ethics approval and consent to participate

Not applicable.

\section{Consent for publication}

Not applicable.

\section{Competing interests}

The authors declare that they have no competing interests" in this section.

\section{Author details}

'Beijing Advanced Innovation Center for Food Nutrition and Human Health, Beijing Technology and Business University, Fucheng Road, Beijing 100048, China. ${ }^{2}$ Chemistry and Materials Engineering, Beijing Technology and Business University, 11 Fucheng Road, Haidian District, Beijing 100048, China. ${ }^{3}$ Beijing Key Lab of Plant Resource Research and Development, Beijing Technology and Business University, Fucheng Road, Beijing 100048, China.

${ }^{4}$ Yunnan Baiyao Group Co., Ltd, Kunming 650000, China. 
Received: 2 October 2020 Accepted: 22 December 2020 Published online: 14 January 2021

\section{References}

1. Guo HB, Cui XM, An N, Cai GP. Sanchi ginseng (Panax notoginseng (Burkill) F. H. Chen) in China: distribution, cultivation and variations. Genet Resour Crop Ev. 2010;57(3):453-60

2. Peng M, Yi YX, Zhang T, Ding Y, Le J. Stereoisomers of Saponins in Panax notoginseng (Sanqi): a review. Front Pharmacol. 2018;9(9):1-18.

3. Xiong Y, Chen L, Man J, Hu Y, Cui X. Chemical and bioactive comparison of Panax notoginseng root and rhizome in raw and steamed forms. J Ginseng Res. 2019;43(3):385-93

4. Yang $X$, Xiong $X$, Wang $H$, Wang J. Protective effects of Panax notoginseng saponins on cardiovascular diseases: a comprehensive overview of experimental studies. Evid Based Complement Alternat Med. 2014;2014: 204840

5. Xu D, Huang $P, Y u Z$, Xing DH, Ouyang $S$, Xing G. Efficacy and safety of Panax notoginseng Saponin therapy for acute Intracerebral hemorrhage, meta-analysis, and mini review of potential mechanisms of action. Front Neurol. 2014;5:274

6. He X, Deng FJ, Ge JW, Yan XX, Pan AH, Li ZY. Effects of total saponins of Panax notoginseng on immature neuroblasts in the adult olfactory bulb following global cerebral ischemia/reperfusion. Neural Regen Res. 2015; 10(9):1450-6.

7. Wang CZ, McEntee E, Wicks S, Wu JA, Yuan CS. Phytochemical and analytical studies of Panax notoginseng (Burk.) F.H. Chen. J Nat Med-Tokyo. 2006;60(2):97-106

8. Sun H, Yang Z, Ye Y. Structure and biological activity of protopanaxatrioltype saponins from the roots of Panax notoginseng. Int Immunopharmacol. 2006;6(1):14-25

9. Liu L, Zhu L, Zou Y, Liu W, Zhang X, Wei X, et al. Panax notoginseng Saponins promotes stroke recovery by influencing expression of Nogo-a NgR and p75NGF, in vitro and in vivo. Biol Pharm Bull. 2014;37(4):560-8.

10. Wu Y, Wang D. Structural characterization and DPPH radical scavenging activity of an Arabinoglucogalactan from Panax notoginseng root. J Nat Prod. 2008;71(2):241-5

11. Park SE, Na CS, Yoo SA, Seo SH, Son HS. Biotransformation of major ginsenosides in ginsenoside model culture by lactic acid bacteria. J Ginseng Res. 2017:41(1):36-42.

12. Zhao H, Han Z, Li G, Zhang S, Luo Y. Therapeutic potential and cellular mechanisms of Panax notoginseng on prevention of aging and cell senescence-associated diseases. Aging Dis. 2017:8(6):721-39.

13. Yang $X$, Wang $R$, Zhang S, Zhu W, Tang J, Liu J, et al. Polysaccharides from Panax japonicus C.a. Meyer and their antioxidant activities. Carbohydr Polym. 2014;101:386-91.

14. Ohtani K, Mizutani K, Hatono S, Kasai R, Sumino R, Shiota T, et al. Sanchinana, a Reticuloendothelial system activating Arabinogalactan from Sanchiginseng. Planta Med. 1987;53(2):166-9.

15. Gao H, Wang F, Lien EJ, Trousdale MD. Immunostimulating polysaccharides from Panax notoginseng. Pharm Res. 1996:13:1196-200.

16. Chen T, Gu L, Zhong YY, Chen Y, Zhang L, Zhang AR, Li HY, et al. Administration of polysaccharide from Panax notoginseng prolonged the survival of H22 tumor-bearing mice. Onco Targets Ther. 2016;9:3433-41.

17. My PLT, My HTK, Phuong NTX, Dat TD, Thanh VH, Nam HM, et al. Optimization of enzyme-assisted extraction of ginsenoside Rb1 from Vietnamese Panax notoginseng (BURK.) F.H. Chen roots and anticancer activity examination of the extract. Sep Sci Technol. 2020:1-12.

18. Feng $\mathrm{S}$, Cheng $\mathrm{H}, \mathrm{Xu} Z \mathrm{Z}$, Shen $\mathrm{S}$, Yuan M, Liu J, et al. Thermal stress resistance and aging effects of Panax notoginseng polysaccharides on Caenorhabditis elegans. Int J Biol Macromol. 2015;81:188-94.

19. Sung SK, Rhee YK, Cho CW, Kim YC, Lee OKH, Hong HD. Physicochemical properties and antioxidative activity of fermented rhodiola sachalinensis and Korean red ginseng mixture by lactobacillus acidophilus. Korean J Food Nutr. 2013;26(3):358-65.

20. Bai $Y$, Ganzle MG. Conversion of ginsenosides by Lactobacillus plantarum studied by liquid chromatography coupled to quadrupole trap mass spectrometry. Food Res Int. 2015;76(Pt 3):709-18.

21. Nout MJR, Motarjemi Y. Assessment of fermentation as a household technology for improving food safety: a joint FAO/WHO workshop. Food Control. 1997;8(5-6):221-6.
22. Liu PP, Yu D, Wang CT, Yang F, Li M, Zhang JC. Study on anti-aging activity of polysaccharides in Sanqi fermentation liquor. China Surfactant Deterg Cosmet. 2019;49(06):369-76.

23. Liu PP, Yu D, Wang CT, Zhao D, Jc Z, Li M. Optimization of microbial fermentation extraction process of Panax notoginseng and evaluation of its anti-inflammatory effect. Food Res Dev. 2019;40(18):71-8.

24. Duval C, Cohen C, Chagnoleau C, Flouret V, Bourreau E, Bernerd F. Key regulatory role of dermal fibroblasts in pigmentation as demonstrated using a reconstructed skin model: impact of photo-aging. PLoS One. 2014;9(12): e114182.

25. Singh R, Devi S, Gollen R. Role of free radical in atherosclerosis, diabetes and dyslipidaemia:larger-than-life. Diabetes Metab Res Rev. 2015:31(2):113-26.

26. Weisfelner ME, Gottlieb AB. The role of apoptosis in human epidermal keratinocytes. J Drugs Dermatol. 2003:2(4):385-91.

27. Nimse SB, Pal D. Free radicals, natural antioxidants, and their reaction mechanisms. RSC Adv. 2015;5(35):27986-8006.

28. Barbosa MR, Sampaio IH, Teodoro BG, Sousa TA, Zoppi CC, Queiroz AL, et al. Hydrogen peroxide production regulates the mitochondrial function in insulin resistant muscle cells: effect of catalase overexpression. Biochim Biophys Acta. 2013;1832(10):1591-604

29. Lopez-Alarcon C, Denicola A. Evaluating the antioxidant capacity of natural products: a review on chemical and cellular-based assays. Anal Chim Acta. 2013;763:1-10.

30. Liu Z, Li Y, Song H, He J, Li G, Zheng Y, et al. Collagen peptides promote photoaging skin cell repair by activating the TGF- $\beta / S$ mad pathway and depressing collagen degradation. Food Funct. 2019;10(9):6121-34.

31. Yu XH, Liu Y, Wu XL, Liu LZ, Fu W, Song DD. Isolation, purification, characterization and immunostimulatory activity of polysaccharides derived from American ginseng. Carbohydr Polym. 2017;156:9-18.

32. Wang JR, Yau LF, Gao WN, Liu Y, Yick PW, Liu L, et al. Quantitative comparison and metabolite profiling of saponins in different parts of the root of Panax notoginseng. J Agric Food Chem. 2014;62(36):9024-34.

33. Zhang M, Zhang H, Li H, Lai F, Li X, Tang Y, et al. Antioxidant mechanism of betaine without free radical scavenging ability. J Agric Food Chem. 2016; 64(42):7921-30.

34. Mosmann T. Rapid colorimetric assay for cellular growth and survival: application to proliferation and cytotoxicity assays. J Immunol Methods. 1983;65(1-2):55-63.

35. Cao XN, Shen $\sqcup$, Wu SD, Yan C, Zhou Y, Xiong G, et al. Urban fine particulate matter exposure causes male reproductive injury through destroying blood-testis barrier (BTB) integrity. Toxicol Lett. 2017;266:1-12.

36. Zhang LX, Xu Y, Li Y, Bao T, Gowed V, Chen W. Protective property of mulberry digest against oxidative stress - A potential approach to ameliorate dietary acrylamide-induced cytotoxicity. Food Chem. 2017;230: 306-15.

37. Yuan XH, Fan YY, Yang CR, Gao XR, Jun H. Progesterone amplifies oxidative stress signal and promotes $\mathrm{NO}$ production via $\mathrm{H} 2 \mathrm{O} 2$ in mouse kidney arterial endothelial cells. J Steroid Biochem Mol Biol. 2016;155(Pt A):104-11.

38. Dong Y, Cui PF, Li ZJ, Zhang SC. Aging asymmetry: systematic survey of changes in age-related biomarkers in the annual fish Nothobranchius guentheri. Fish Physiol Biochem. 2017:43(2):309-19.

39. Wu JH, Sun BG, Luo XL, Zhao MM, Zheng FP, Sun JY, et al. Cytoprotective effects of a tripeptide from Chinese Baijiu against AAPH-inducedoxidative stress in HepG2 cells via Nrf2 signaling. RSC Adv. 2018;08(20):10898-906.

40. Lin YW, Mou YC, Su CC, Chiang BH. Antihepatocarcinoma activity of lactic acid bacteria fermented Panax notoginseng. J Agric Food Chem. 2010;58(15): 8528-34.

41. Yeh CT, Yen GC. Induction of hepatic antioxidant enzymes by phenolic acids in rats is accompanied by increased levels of multidrug resistanceassociated protein 3 mRNA expression. J Nutr. 2006;136(1):11-5.

42. Cho HS, Lee MH, Lee JW, No KO, Park SK, Lee HS, et al. Anti-wrinkling effects of the mixture of vitamin C, vitamin E, pycnogenol and evening primrose oil, and molecular mechanisms on hairless mouse skin caused by chronic ultraviolet B irradiation. Photodermatol Photoimmunol Photomed. 2007;23(5):155-62.

43. Luckett LR, Gallucci RM. Interleukin-6 (IL-6) modulates migration and matrix metalloproteinase function in dermal fibroblasts from IL-6KO mice. $\mathrm{Br} J$ Dermatol. 2010;156(6):1163-71.

44. Bae JY, Choi JS, Choi YJ, Shin SY, Kang SW, Jun Han S, et al. Epigallocatechin gallate hampers collagen destruction and collagenase activation in 
ultraviolet-B-irradiated human dermal fibroblasts: involvement of mitogenactivated protein kinase. Food Chem Toxicol. 2008;46(4):1298-307.

45. Oliveira MM, Ratti BA, Daré RG, et al. Dihydrocaffeic acid prevents UVBinduced oxidative stress leading to the inhibition of apoptosis and MMP-1 expression via p38 signaling pathway. 2019;2019:2419096.

46. Kammeyer A, Luiten RM. Oxidation events and skin aging. Ageing Res Rev. 2015;21:16-29.

47. Feng $\mathrm{Sl}$, Cheng $\mathrm{HR}, \mathrm{Xu} Z$ Z, et al. Antioxidant and anti-aging activities and structural elucidation of polysaccharides from Panax notoginseng root. 2019.

48. Chen $H$, Wang $Y$, Jiao FZ, et al. Sinomenine attenuates acetaminopheninduced acute liver injury by decreasing oxidative stress and inflammatory response via regulating TGF-B/Smad pathway in vitro and in vivo. 2020, 2020(default):2393-403.

49. Ham SA, Hwang JS, Kang ES, Yoo T, Lim HH, Lee WJ, et al. Ethanol extract of protects skin keratinocytes against ultraviolet B-induced photoaging by suppressing production of reactive oxygen species. Biosci Biotechnol Biochem. 2015;79(5):760-6.

\section{Publisher's Note}

Springer Nature remains neutral with regard to jurisdictional claims in published maps and institutional affiliations.

Ready to submit your research? Choose BMC and benefit from:

- fast, convenient online submission

- thorough peer review by experienced researchers in your field

- rapid publication on acceptance

- support for research data, including large and complex data types

- gold Open Access which fosters wider collaboration and increased citations

- maximum visibility for your research: over $100 \mathrm{M}$ website views per year

At $\mathrm{BMC}$, research is always in progress.

Learn more biomedcentral.com/submissions 